\title{
El Covid-19 y la escuela en casa
}

\section{Covid-19 and the school at home}

LEAL-REYES, Rosa Gabriela, NAVARRO-LEAL, Verónica Yudith, CRUZ-AGUILAR, María de Lourdes y ACOSTA-MONTES DE OCA, Mónica

Universidad Autónoma de Tamaulipas (UAMCEH UAT)- Unidad Académica Multidisciplinaria de Ciencias, Educación y Humanidades.

ID $1^{\mathrm{er}}$ Autor: Rosa Gabriela, Leal-Reyes / ORC ID: 0000-0003-1881-2448, CVU CONACYT ID: 491805

ID $1^{\mathrm{er}}$ Coautor: Verónica Yudith, Navarro-Leal / ORC ID: 0000-0002-9574-8358, CVU CONACYT ID: 1073173

ID $2^{\text {do }}$ Coautor: María De Lourdes, Cruz-Aguilar / ORC ID: 0000-0001-6648-6208 CVU CONACYTD ID: 221889

ID $3^{\text {er }}$ Coautor: Mónica, Acosta-Montes De Oca / ORC ID: 0000-0002-4193-9781, CVU CONACYT ID: 633866

\section{Resumen}

El ser humano, se enfrenta a una amenaza mundial, el COVID 19, para la cual, hasta hoy, no existe vacuna, lo que ha obligado a las personas que trabajan en actividades no esenciales a recluirse a un confinamiento en su casa. Las autoridades escolares, implantaron el Programa la Escuela en Casa, que trajo situaciones inéditas y problemas a resolver.

COVID 19, Escuela en casa, Problemas

\begin{abstract}
The human being faces a global threat, COVID 19 , for which, until today, there is no vaccine, which has forced people who work in nonessential activities to seclude themselves in a confinement at their home. School authorities implemented The School at Home Program, which brought unprecedented situations and problems to solve.
\end{abstract}

\section{COVID 19, School at home, Problems}

Citación: LEAL-REYES, Rosa Gabriela, NAVARRO-LEAL, Verónica Yudith, CRUZ-AGUILAR, María de Lourdes y ACOSTA-MONTES DE OCA, Mónica. El Covid-19 y la escuela en casa. Revista de Tecnología y Educación. 2020. 4-12: 15.22

\footnotetext{
$\dagger$ Investigador contribuyendo como primer autor.
} 


\section{Introduccion}

El 14 de marzo, la Secretaría de Salud y la Secretaría de Educación Pública en Tamaulipas, confirmaron una directiva que hacía tiempo sospechábamos: que las clases quedarían suspendidas a partir del 20 de marzo y se reanudarían hasta el 20 de abril, debido a la epidemia del Coronavirus. Sin embargo, pasó el mes, llegaron las vacaciones de Samana Santa y la población, maestros y estudiantes, nos confinamos y el trabajo en la escuela quedó suspendido definitivamente sin fecha de retorno. Entonces y en consecuencia, a nivel federal, la Secretaría de Educación Pública (SEP) estableció el Programa Escuela en Casa.

Mientras tanto, las cifras sobre contagios, recuperaciones y defunciones, inundó la pantalla chica, las difusoras de radio y las noticias en la red. No hay conversación en donde no se pronuncie la palabra COVID o Coronavirus, que se convirtió en una pandemia. Los niños pasaron de ser hijos, a ser alumnos de sus padres y los padres transitaron a convertirse, como por arte de magia en profesores. La recámara o el comedor pasaron a ser el salón de clase y la sala el área de recreo.

\section{Preguntas de investigacion}

En esta situación, las primera preguntas, inmediatas y obligadas son, sin lugar a dudas: ¿Qué es COVID 19? y ¿Qué es lo que ocurre en casa?

\section{Marco teorico}

\section{Covid 19}

De acuerdo con la Organización Mundial de la Salud (OMS), los coronavirus son una extensa familia de virus que pueden causar enfermedades tanto en animales como en humanos. En los humanos, se sabe que varios coronavirus causan infecciones respiratorias que pueden ir desde el resfriado común hasta enfermedades más graves como el síndrome respiratorio de Oriente Medio (MERS) y el síndrome respiratorio agudo severo (SRAS). El coronavirus que se ha descubierto más recientemente causa la enfermedad por coronavirus COVID-19.
Los coronavirus son una familia de virus que causan enfermedades (desde el resfriado común hasta enfermedades respiratorias más graves) y circulan entre humanos y animales.

Específicamente, La COVID-19 es la enfermedad infecciosa causada por el coronavirus que se ha descubierto más recientemente. Tanto este nuevo virus como la enfermedad que provoca eran desconocidos antes de que estallara el brote en Wuhan (China) en diciembre de 2019. Actualmente la COVID-19 es una pandemia que afecta a numerosos países de todo el mundo (OMS 2020).

Los síntomas más habituales de la COVID-19 son fiebre, tos seca y cansancio. Otros síntomas menos frecuentes que afectan a algunos pacientes son dolores y molestias, congestión nasal, dolor de cabeza, conjuntivitis, dolor de garganta, diarrea, pérdida del gusto o el olfato y las erupciones cutáneas o cambios de color en los dedos de las manos o los pies. Estos síntomas suelen ser leves y comienzan gradualmente. Algunas de las personas infectadas solo presentan síntomas levísimos. (OMS 2020)

La mayoría de las personas (alrededor del $80 \%$ ) se recuperan de la enfermedad sin necesidad de tratamiento hospitalario. Alrededor de 1 de cada 5 personas que contraen la COVID-19 acaba presentando un cuadro grave y experimenta dificultades para respirar. Las personas mayores y las que padecen afecciones médicas previas como hipertensión arterial, problemas cardiacos o pulmonares, diabetes o cáncer tienen más probabilidades de presentar cuadros graves. Sin embargo, cualquier persona puede contraer la COVID-19 y caer gravemente enferma.

Las personas de cualquier edad que tengan fiebre o tos y además respiren con dificultad, sientan dolor u opresión en el pecho o tengan dificultades para hablar o moverse deben solicitar atención médica inmediatamente. Si es posible, se recomienda llamar primero al profesional sanitario o centro médico para que estos remitan al paciente al establecimiento sanitario adecuado. (OMS 2020) En este caso, se trata del SARS-COV2. Apareció en China en diciembre pasado y provoca una enfermedad llamada COVID-19, que se extendió por el mundo y fue declarada pandemia global por la Organización Mundial de la Salud (OMS 2020)

LEAL-REYES, Rosa Gabriela, NAVARRO-LEAL, Verónica Yudith, CRUZ-AGUILAR, María de Lourdes y ACOSTA-MONTES DE OCA, Mónica. El Covid-19 y la escuela en casa. Revista de Tecnología y Educación. 2020. 
La principal forma de propagación de la COVID-19 es a través de las gotículas respiratorias expelidas por alguien que tose o que tiene otros síntomas como fiebre 0 cansancio. Muchas personas con COVID-19 presentan solo síntomas leves. Esto es particularmente cierto en las primeras etapas de la enfermedad. Es posible contagiarse de alguien que solamente tenga una tos leve y no se sienta enfermo (OMS 2020).

Según algunas informaciones, las personas sin síntomas pueden transmitir el virus. Aún no se sabe con qué frecuencia ocurre. La OMS está estudiando las investigaciones en curso sobre esta cuestión y seguirá informando sobre las conclusiones que se vayan obteniendo.

Practicar la higiene respiratoria y de las manos es importante en TODO momento y la mejor forma de protegerse a sí mismo y a los demás. Cuando sea posible, mantenerse al menos un metro de distancia entre una y otra persona. Esto es especialmente importante si se está al lado de alguien que esté tosiendo o estornudando. Dado que es posible que algunas personas infectadas aún no presenten síntomas o que sus síntomas sean leves, conviene mantenerse a buena distancia física de todas las personas si se encuentra en una zona donde circule el virus de la COVID-19.

En el mundo, de acuerdo a la OMS, ha habido 33, 200000 personas contagiados por el COVID 19 y han fallecido 999, 000 personas. En México, la cifra asciende a 730000 enfermos de COVID 19, hasta el día de hoy y han ocurrido 76, 430 muertes por este virus, según la Secretaría de Salud. En Tamaulipas hasta el 27 de septiembre del 2020, un total de 24,913 enfermos de COVID19 y han ocurrido 1850 muertes por esta enfermedad.

Así, se declaró la emergencia por motivos de salud y se dio la orden de quedarse en casa, para evitar contagiar o ser contagiado, se cerraron las escuelas de todos los niveles educativos, oficinas de gobierno y todas las actividades que se consideraron no esenciales. Y tratamos de quedarnos en casa el mayor tiempo posible. Han transcurrido, no cuarenta ni ochenta días, más, incluyendo hasta este momento, dos períodos vacacionales en el confinamiento y maestros, padres e hijos, están percibiéndose con mucho estrés, provocado por el confinamiento y el temor a presentar la enfermedad.
Una enfermedad que en Ciudad Victoria, Tamaulipas, ha ocasionado más de 8,208 casos de enfermos y 53 muertes. Nuestra ciudad y nuestro estado, son solamente un referente geográfico, pues esta pandemia, ha sacudido a todo el paìs y a todo el mundo. En Argentina, Artopoulos, A (2020), sostiene que en el mundo hay 1600 millones de alumnos en 188 países cuyos sistemas escolares se vieron obligados a cerrar sus puertas, lo que afectó al 91.3\% del total de la inscripción de alumnos en todo el mundo.

Por ejemplo, en Chiapas, según Mérida y Acuña(2020) en un artículo denominado Análisis de los Programas Educativos Emergentes, hacen notar que los programas educativos emergentes ni va de acuerdo con la realidad ni en todas las regiones del país sucede la misma situación, que existen brechas educativas de región a región. No es lo mismo el acceso a las tecnologías de la información del Estado de Nuevo León que lo que sucede en el Estado de Chiapas, por ejemplo. Murillo y Duck (2020), coinciden en este punto de análisis Murillo y Duck, quienes sostienen que la brecha educativa se incrementará por la interrupción del aprendizaje, alimentación insuficiente, falta de preparación de los padres para apoyar a sus hijos en las tareas educativas a través de los aparatos electrónicos, si los tuvieran.

En enero del 2020, según Amador, R. (2020), la OMS, ha alertado sobre los efectos del nuevo virus y que ha alcanzado hasta esa fecha, a contagiar a millones de personas, por lo que ha implementado la necesidad de trabajar a disctancia con un sinnúmero de problemas a los cuales padres de familia y docentes, se ven enfrentados e imposibiltados, en muchos casos, para resolver. En su artículo titulado Aprende en casa con Sana Distancia, en tiempo del COVID 19 , alerta sobre las condiciones de 3600 millones de personas en el mundo que no tienen conectividad a internet, problemas de desnutrición y servicios de salud ineficientes. De LeónTapia y Vélez,(2020) en su artículo denominado "Los retos de la educación presencial ante la contingencia sanitaria del COVID 19, señalan cómo se hace necesario el manejo, dominio e implementación de estrategias tecnológicas por parte de los profesores, para apoyar a los estudiantes de una mejor manera, los retos que implica el impartir enseñanza a distancia, lo que los impulsa a superar el desconcierto natural que produce el miedo y temor ante la educación a distancia.

LEAL-REYES, Rosa Gabriela, NAVARRO-LEAL, Verónica Yudith, CRUZ-AGUILAR, María de Lourdes y ACOSTA-MONTES DE OCA, Mónica. El Covid-19 y la escuela en casa. Revista de Tecnología y Educación. 2020. 


\section{Metodologia}

Ahora, habiendo transcurrido un primer período de confinamiento de tres meses, ya han brotado los primeros efectos del confinamiento.

Algunos de los primeros testimonios de esta nueva y sorpresiva experiencia, se exponen en el siguiente apartado.

La metodología a utilizar es de tipo cualitativo, testimonial, mediante la técnica de la entrevista, aplicándose una sola ocasión

\section{Entrevistas}

La escuela en casa. Experiencias de padres de familia y profesores durante el confinamiento

\section{Caso 1:}

"Como maestro, me di cuenta de varias cosas interesantes: Los alumnos hombres, que me daban más problemas en la clase presencial porque se distraían fácilmente, platicaban mucho o jugaban con sus compañeros y otros que se salían del salón de clase, ahora, eran los primeros que enviaban sus tareas y actividades en línea, como consecuencia, su promedio subió mucho. Las alumnas que me daban más problemas y se distraían mucho platicando, no subieron de promedio y no enviaron todas las actividades por lo que su promedio bajó.

En los dos grupos con que trabajé este semestre, tenía subgrupos de 5 o 6 alumnos que eran los más aplicados y me entregaban las actividades de trabajo muy rápido y tenían siempre 10. Cuando empezaron las clases en línea 2 ó 3 alumnos de esos subgrupos, mantuvieron su promedio y me entregaban las actividades, pero el resto del grupo, bajó de promedio. Creo que el cambio no se debió a la inteligencia porque las actividades son sencillas, creo que el cambio se debió a que los alumnos necesitan del apoyo de sus compañeros para sentirse motivados a trabajar.

En cada grupo, tuve por lo menos un alumno que tenía problemas de escasez de recursos y como consecuencia, problemas para desarrollar las actividades en línea. Me enteré que muchos maestros no tuvieron ninguna consideración por su situación económica.
Otros vivían en ejidos y no tenían computadora y con poco acceso a internet, por lo que me vi obligado a utilizar Watts App, con lo que trabajo mucho mejor que con la plataforma Google Classroom que nos pidieron que usáramos, aunque varios maestros no quisieron cambiar la forma de envío de trabajos".

\section{Caso 2:}

"Mi hijo cursa el primer grado de primaria en un colegio particular. Tiene 14 compañeros y recibe clases de Inglés, Computación, Ciencias, Español, Matemáticas y Educación Física. Tengo otro hijo, que en junio cumplió un año y mi esposa es maestra y tiene que trabajar desde casa, también.

Mi hijo mayor, tiene 7 años y es un niño que fue planeado y esperado desde antes de su concepción. Al llegar la fecha de inscribirlo en la primaria, estudiamos las diferentes posibilidades y elegimos la escuela que para nosotros era la mejor.

Observando las clases de mi hijo, me di cuenta que la maestra no podía dar la clase, como que imagino que ella estaba acostumbrada a estar exponiendo y los niños escuchando, por tres cosas:

Primero: En la clase en línea, el volumen de la voz tanto del niño como el de la maestra, es el mismo, por lo que ella no podía usar su voz como medio de control y al no poder hablar más fuerte que los niños, no podía callarlos, creo que ella basaba su autoridad con la voz, ahora, bajo el cuidado y observación de los padres, no los podía callar.

Segundo: Como los niños no estaban en el salón, los niños se dieron cuenta que la mayor autoridad no era la maestra, sino los padres, o quien los estuviera cuidando.

Tercero: La maestra sabía que estaba siendo observada y posiblemente grabada por los padres, por lo que se percibía que no encontraba forma de hacer callar a las niñas y niños que intentaban contarle cosas sobre su día, cosas que les sucedían o cosas por el estilo, lo que hacía que se perdiera mucho tiempo con pláticas monopolizadas por uno o dos niños". 


\section{Caso 3:}

"Como maestra, la Educación Inicial se basa en la observación y en el comportamiento del niño, su desarrollo, sus gustos, intereses y habilidades y el contacto entre los niños y sus maestras. Al no observarlos directamente, no se logra aplicar correctamente el programa. Todas las actividades que se planifican dependen, ahora, completamente de los padres, si las quieren o no aplicar y la forma y momento que pueden y como pueden hacerlo.

Algunos padres no le dan la importancia que tienen estas actividades, les parece que son de más, de relleno, no comprenden que son básicas para coadyuvar al desarrollo psicomotriz, afectivo y cognoscitivo de sus hijos, mientras que hay padres de familia que le dan la debida importancia que reviste cada actividad, pero la mayoría no lo hace, le dan mayor importancia y tiempo, a las actividades de los hijos mayores que ya cursan grados escolares más altos. Los recursos necesarios se limitan a lo que haya al alcance, porque se está sin poder salir de casa. Las evaluaciones son cualitativas y se otorgan ahora, en cuarentena, de acuerdo a lo que los padres nos platican que el niño hace.

Los vínculos de apego entre alumnos y maestras se empiezan a diluir al no tener comunicación constante".

\section{Caso 4:}

"Las clases en línea requieren de la disposición del padre durante la clase completa, lidiar con las interrupciones constantes de otros padres, alumnos y los problemas con la tecnología que se utiliza.

También implica dividir a la familia, si se tienen hijos de diferente grado escolar, para no distraer al niño que está asistiendo a clase, esto es, la mamá se va con un niño a otro espacio y el papá se queda con el otro... ¿y si tuvieran 3 ó más hijos?

Yo observé la rigidez de la maestra en el horario, por ejemplo, se impartía el tema y el niño tenía que entregarlo en los siguientes 5 minutos, si no, ya no era aceptado.
También experimenté que la intimidad de la familia fue vulnerada, observé que el niño se confunde, al no distinguir con claridad si la escuela era su casa o si ahora la casa se convirtió en escuela".

\section{Caso 5:}

"Como mamá de un niño que asiste a la guardería, debo decir que la maestra no conoce bien la tecnología de la información que utiliza y se le dificulta mucho acceder a ella. Los niños desconocen las canciones que su maestra canta, y no se lleva el mismo horario en casa que en la escuela.

El trato al niño es diferente, ya que la casa no está equipada para darle libertad como en el CENDI, por ejemplo: el niño puede gatear en el salón porque el piso está recubierto fomi y no hay algo que sea peligroso a su alcance, para su gateo, a pero en casa, si está dentro de un corralito o periquera, no entenderá las actividades a aplicar, las madres no tenemos la música que la maestra usa. Aparte, no solo debo cuidar a mi niño de guardería, sino que también debo atender a mi otro niño que también está, al mismo tiempo, con las clases en línea, aparte mis quehaceres de limpieza y elaboración de alimentos, que como madre, me corresponden".

\section{Caso 6:}

"Soy docente en una institución de educación superior y a la vez, apoyo a mis hijas cuidando a mis nietos cuando ellas trabajan. Generalmente me desocupo a las 4 de la tarde, pero ahora con la cuarentena, una de ellas, tiene un trabajo esencial, sale de su trabajo hasta las 9 de la noche, así que tengo que compaginar mi trabajo como maestra con el trabajo de abuela. Uno de los problemas que enfrenté en este período escolar, fue el horario escolar, chocaba con el horario de cuidados infantiles. Y en ocasiones, al estar trabajando en línea con mis estudiantes, la nieta hacía aparecer su carita en la pantalla, en lugar de la mía, cuando me paraba a tomar agua. El tiempo, se difuminaba muy fácilmente y hasta los estudiantes perdían la noción de su transcurrir, pues en ocasiones, me mandaban mensajes a las doce de la noche, y al escuchar el sonido de aviso de mensaje, se me quitaba el sueño. Entonces, el tiempo fue otro factor, importante. 
Por otra parte, la situación me ocasionó mucho estrés porque antes de contactar con los estudiantes, me ocupaba de que el área que mis estudiantes vieran de mi casa, estuviera presentable y muy limpia.

Otro problema fue, que el $20 \%$ de los estudiantes, se relajó en cuanto a la obligatoriedad de las tareas y actividades a desarrollar. Hacían todo como querían, no como se les especificaba, y al final ese $20 \%$ dijo, prácticamente que le hiciera como quisiera, que ya habían avisado que nadie reprobaría.

El $40 \%$ de los estudiantes siempre estuvieron muy atentos $y$ fueron tan responsables como si la clase fuera presencial.

Pero hubo un $40 \%$ que vive fuera de la ciudad, en el sector rural donde no hay internet y si lo hubiese, ellos no tienen computadora para trabajar. Lo que fue muy efectivo en cuanto a la comunicación, fue el uso de teléfono celular y su aplicación de Watts App. El gran problema que percibo, como muy delicado, es que hay materias cien por ciento prácticas y difícilmente se pueden hacer en casa".

\section{Caso 7:}

"Soy madre de un estudiante de Medicina, quiero decir que si las clases de Medicina, en salón o en hospital son difíciles, en la casa es mucho peor. Quedé traumada. Solo porque ya va a terminar, le falta un semestre para acabar, si no, lo sacaba. Quedó flaquísimo, se esforzó al límite, y al final terminó super enojado, pues de todos los compañeros que iniciaron en su generación, solamente quedan 4 sin materias pendientes. Lleva tres días seguidos, dormido, solo se levanta a comer y al baño, es muy duro".

\section{Caso 8:}

"Atiendo grupos de Educación Cívica y Ética, tengo 4 grupos y mi escuela está ubicada en una zona de bajos recursos, aquí en la ciudad, si durante los cursos ordinarios, batallo porque las familias de donde provienen mis estudiantes, aparte de ser de bajos recursos, tienen bajo nivel educativo, ahora, ¿con la pandemia, encerrados en casa y con problemas de alimentación? Ya quiero que todo esto acabe, esto no debe ser, no estoy preparada para enfrentar esta situación. Por fortuna, pronto me voy a jubilar y me quitaré el estrés".

\section{Caso 9:}

"La experiencia como maestra es más gratificante y sencilla de manera presencial, ya que en el contacto cotidiano con los alumnos podemos aprender unos de otros, fortalecer el aprendizaje, opinar, debatir, oponerse a algunos argumentos, etc. La evaluación es más sencilla ya que al ver al alumno lo identificas y el docente se puede dar cuenta de quién asiste o no a clases, quien participa, etcétera.

En línea no me es tan placentero ya que un mismo trabajo lo pueden presentar varias veces, sólo cambiando el formato, otros sólo mandan el trabajo y quieren 10 aunque esté mal hecho o si no lo enviaron en el tiempo estipulado, aunque eso del tiempo debería de ser flexible, ya que hay alumnos que no tienen internet o luz en casa.

Otros no tienen computadora, otros no están acostumbrados a usar las herramientas tecnológicas educativas o no podían tener acceso a sus correos institucionales o a ciertas plataformas para realizar los trabajos.

Hubo alumnos que se apoyaron mucho en la ayuda que los representantes de grupo les ofrecían para mandar tareas electrónicas, revisar trabajos, hacer exámenes en línea, dar una exposición sobre un tema, etcétera.

También es cierto, que aunque pocos pero si había representantes de grupo que no contaban con lo suficiente económicamente hablando para hacer sus tareas y eran otros compañeros los que a ellos los apoyaban.

Hubo maestros muy duros en la forma de evaluar, ya que no daban oportunidad de recibir el trabajo después de tiempo y aunque los alumnos mandaban la tarea, los docenes ya no la recibían.

Había docentes también muy comprensivos incluso hubo una maestra que se ofreció a ir hasta las casas de sus alumnos por las tareas.

Otros, pedían impresiones o material muy caro o que se debía de salir de casa, aunque la indicación era muy clara, no pedir a los alumnos tareas en exceso ni nada material, todo electrónico. 
Hubo chicos, que realmente la estaban pasando difícil, ya que sus padres se quedaron sin empleo, y ellos tuvieron que salir a buscar algún trabajo o vender sus pertenencias más preciadas como el celular o computadora.

Los chicos tuvieron que suspender prácticas, servicios social, porque muchos lo hacen en grandes empresas u hospitales.

La mayoría de los alumnos se esforzaba por cumplir con las tareas pero hubo otros pocos que aunque el docente diera muchas oportunidades, ellos preferían reprobar. Otros chicos decían que para qué estudiar, si ya todo se iba a acabar, que no servía de nada esforzarse, que cada vez el mundo estaba peor, que siendo buenos o cumpliendo, no salen adelante, que si se dejaban, cualquiera los pisotearía que eso es lo que les debían enseñar en la escuela.

Algunos interrumpieron su educación ya que terminaron el último semestre de CBTis en línea pero que no había condiciones para inscribirse a la universidad.

Que lo único bueno del semestre era la beca que les mandaba AMLO, la beca Benito Juárez. Los chicos de CBTis también se ahorraron las prácticas y el servicio social. Ellos tuvieron su gallo de graduación, y una graduación virtual donde se pasó lista de cada grupo, a cargo del tutor y se hicieron varias reseñas fotográficas de cada uno de los grupos que egresaba, se autonombraron: la generación del COVID. En una secundaria donde tampoco hubo graduación los alumnos de un grupo, se mandaron hacer playeras iguales $\mathrm{y}$ todos enfrente de la entrada principal de su escuela se pusieron su playera, tapabocas y se tomaron la foto de graduación. Muy triste comentaban, aunque estaban realmente sin mucho cuidado, ya que casi estaban agarrados de las manos".

\section{Reflexión}

A partir de estos primeros comentarios expuestos, se pueden deducir algunas reflexiones muy generalizadas pero que pretenden ser un diagnóstico inicial de un problema que probablenente se prolongue por varios meses o años, para que sirva de referente en la búsqueda de estrategias alternas para la Escuela en Casa:
- $\quad$ Algunos maestros no estaban preparados pedagógicamente para dirigir grupos en línea.

- $\quad$ Hay maestros han visto que su autoridad y control se han diluido.

- Muchos maestros enfrentan serios problemas para evaluar a sus estudiantes, lo que coincide con Mérida y Acuña (2020) quienes afirman que tanto los estudiantes como los docentes, interiorizaron la necesidad de organizarse mejor y adaptarse más rápido ante la contngencia del COVID 19.

- Muchos estudiantes se desconcertaron ante el cambio.

- $\quad \mathrm{Ni}$ los estudiantes, no los padres ni muchos profesores, estudiantes estaban preparados y equipados tecnológicamente para las clases en línea, lo que ha contribuído a que un gran número de alumnos, se conviertan en autodidactas (Mérida y Acuña (2020).

- Los estudiantes modificaron sustancialmente sus comportamientos.

- La mayoría de los padres no estaban preparados para apoyar a sus hijos en la escuela en casa.

- Muchos hogares no estaban equipados para clases en casa. El trabajo doméstico se multiplicó para las amas de casa.

- Por su propio peso, puedalgunas primeras percepciones de lo que en inferirse algunas primeras percepciones de lo que en el futuro inmediato ocurrirá:

- Se organizarán múltiples entrenamientos para la docencia en línea.

- $\quad$ Se diseñarán carreras y cursos completos para realizarse en línea.

- Se replantearán los contenidos programáticos para conservar lo obligadamente necesario.

- $\quad$ Se utilizará más la radio, televisión y la telefonía celular.

- Se multiplicarán las instituciones escolares en línea.

- Se crearán espacios adecuados en casa, para trabajar en línea.

- Se tratará de equipar a las escuelas de todo lo necesario para la sanitización de edificios y aulas, en preparación del retorno a clase, porque hay mucha desigualdad económica y tecnológica entre las diversas regiones del país y del mundo, para eliminar la brecha educativa, Mérida y Acuña (2020) 
- Se implementarán programas de Higiene y Salud en las escuelas

- Los programas de estudio, van a ser depurados y solamente quedarán las materias con los contenidos esenciales. Dichos programas van a registrar un incremento de su uso, debido a que muchas regiones del país carecen de conectividad a la red, lo que ocasiona la brecha digital Murillo y Duck (2020).

- $\quad$ En el aspecto de salud escolar, se piensa que se incrementará el uso de anteojos, debido a los daños que pueda ocasionar la luz azul en los ojos al estar mucho tiempo expuestos a esta radiación.

\section{Referencias}

Amador, R.. (2020). Aprende en casa con \#SanaDistancia en tiempos del COVID 19. Educación y pandemia:una visión académica, 549,8 .

Artopoulos, A. (2020). ¿Qué hicieron los países para continuar con la educación a distancia?. Revista Latinoamericana de Educación Comparada, 17, 11.

De León, I, Tapia, D, Vélez D. (2020). Estudio sobre los retos de la educación presencial a nivel superior ante la contingencia sanitaria del COVID 19. XIKUA Boletín Científico de la Escuela Superior de Tlahuelilpan, 8, 4.

Mérida Martínez, Y. .., \& Acuña Gamboa, L. A. (2020). Covid-19, Pobreza y Educación en Chiapas: Análisis a los Programas Educativos Emergentes. Revista Internacional De Educación Para La Justicia Social, 9, 23.

Murillo, J. (2020). COVID 19 y las Brechas Educativas. Revista Latinoamericana de Educación Inclusiva, 14, 4

OMS. (2020). BROTE DE ENFERMEDAD POR CORONAVIRUS (COVID 19), agosto 2020, de OMS Sitio web: https://www.who.int/es/emergencies/diseases/n ovel-coronavirus-

2019?gclid=Cj0KCQjwl4 $\mathrm{v} 4 \mathrm{BRDaARIsAFjAT}$

PmZBH5BtlFv-

bIOUc7751CAVPdokhVLDLavWReLd1_D0J

E65xCloHoaAp46EALw_wcB
OMS. (2019). Enfermedad por el nuevo coronavirus. agosto 2020, de OMS Sitio web: https://www.google.com/search?q=cifras+del+c ovid +19

OMS. (2020). Cifras del Coronavirus en Tamaulipas. agosto 2020, de OMS Sitio web: https://www.google.com/search?q=coronavirus + cifras+tamaulipas\&oq=CIFRAS+COVID+TA MAULIPAS\&aqs=chrome.1.69i57j013j69i60.1 0266j0j9\&sourceid $=$ chrome \&ie $=U$ UTF-8

Entrevistas de experiencias y opiniones sobre la Escuela en Casa. 